\title{
Appendiceal Carcinoma pN1b TNM Finding v8
}

National Cancer Institute

\section{Source}

National Cancer Institute. Appendiceal Carcinoma pN1b TNM Finding v8. NCI Thesaurus.

Code C134108.

Appendiceal carcinoma in which two to three regional lymph nodes are positive. (from AJCC 8th Ed.) 